\title{
Measurements of bubble size spectra within leads in the Arctic summer pack ice
}

\author{
S. J. Norris ${ }^{1}$, I. M. Brooks ${ }^{1}$, G. de Leeuw ${ }^{2,3,4}$, A. Sirevaag ${ }^{5,6}$, C. Leck $^{7,8}$, B. J. Brooks ${ }^{1}$, C. E. Birch ${ }^{1}$, and \\ M. Tjernström ${ }^{7,8}$ \\ ${ }^{1}$ School of Earth and Environment, University of Leeds, Leeds, UK \\ ${ }^{2}$ Finnish Meteorological Institute, Climate and Global Change Unit, Helsinki, Finland \\ ${ }^{3}$ University of Helsinki, Department of Physics, Helsinki, Finland \\ ${ }^{4}$ TNO, Utrecht, The Netherlands \\ ${ }^{5}$ Geophysical Institute, University of Bergen, Norway \\ ${ }^{6}$ Bjerknes Centre for Climate Research, Bergen, Norway \\ ${ }^{7}$ Department of Meteorology, Stockholm University, Sweden \\ ${ }^{8}$ Bert Bolin Centre for Climate Research, Stockholm University, Stockholm, Sweden
}

Received: 21 September 2010 - Published in Ocean Sci. Discuss.: 4 October 2010

Revised: 1 February 2011 - Accepted: 2 February 2011 - Published: 14 February 2011

\begin{abstract}
The first measurements of bubble size spectra within the near-surface waters of open leads in the central Arctic pack ice were obtained during the Arctic Summer Cloud-Ocean Study (ASCOS) in August 2008 at 87$87.6^{\circ} \mathrm{N}, 1-11^{\circ} \mathrm{W}$. A significant number of small bubbles (30-100 $\mu \mathrm{m}$ diameter) were present, with concentration decreasing rapidly with size from $100-560 \mu \mathrm{m}$; no bubbles larger than $560 \mu \mathrm{m}$ were observed. The bubbles were present both during periods of low wind speed $\left(U<6 \mathrm{~m} \mathrm{~s}^{-1}\right)$ and when ice covered the surface of the lead. The low wind and short open-water fetch precludes production of bubbles by wave breaking suggesting that the bubbles are generated by processes below the surface. When the surface water was open to the atmosphere bubble concentrations increased with increasing heat loss to the atmosphere. The presence of substantial numbers of bubbles is significant because the bursting of bubbles at the surface provides a mechanism for the generation of aerosol and the ejection of biological material from the ocean into the atmosphere. Such a transfer has previously been proposed as a potential climate feedback linking marine biology and Arctic cloud properties.
\end{abstract}

Correspondence to: S. J. Norris

(s.norris@see.leeds.ac.uk)

\section{Introduction}

Bubbles provide an important link between ocean waters and boundary layer clouds. Bursting bubbles at the air-sea interface eject droplets that evaporate to leave aerosol particles consisting of the salts dissolved in sea water along with any other material contained within the ejected droplet (O'Dowd et al., 2008). Such sea-spray aerosol are typically highly hygroscopic (Tang et al., 1997) and act as effective cloud condensation nuclei (CCN) (Andreas and Rosenfeld, 2008). The radiative properties of clouds and their albedo depend strongly on their droplet size spectra, for which CCN concentration is a controlling factor. The properties of the bubble population within surface waters can thus have a direct influence on cloud properties.

Stratus clouds are near-ubiquitous over the Arctic pack ice (north of $80^{\circ}$ ) during the summer months, and are the dominant control on the surface radiation budget (Intrieri et al., 2002). Arctic stratus is poorly represented within numerical models (Curry et al., 2000; Tjernström et al., 2005, 2008; Birch et al., 2009). Their properties are rather different from those of their mid-latitude counterparts. Very low CCN concentrations (Lannerfors et al., 1983; Covert et al., 1996; Bigg et al., 1996; Bigg and Leck, 2001) result in clouds with fewer but larger droplets, and hence different radiative properties (Tjernström et al., 2008). A series of studies (Leck et al., $1996,2001,2004)$ of atmospheric aerosol over pack ice in the central Arctic Ocean has raised questions as to the source of the aerosol particles that act as CCN. Measurements of CCN

Published by Copernicus Publications on behalf of the European Geosciences Union. 
composition (Leck and Persson, 1996a, b) are consistent with aerosol grown from the oxidation products of dimethyl sulphide (DMS). DMS is released in the uppermost ocean when zooplankton graze on phytoplankton around the biologically productive edges of the pack ice area. In the presence of near-ubiquitous low-level arctic stratus and fog during summer, however, the aerosol would be expected to be scavenged by droplets and not survive long enough to grow from nucleation size $(\sim 3 \mathrm{~nm}$ diameter) to CCN size $(\sim 100 \mathrm{~nm})$. Leck and Bigg (1999) found no sulphuric acid $\left(\mathrm{H}_{2} \mathrm{SO}_{4}\right)$ in aerosol smaller than about $50 \mathrm{~nm}$, implying either recent formation or growth from something other than DMS oxidation products. Leck and Bigg (2005a, b) described observations of particles collected within the atmospheric surface layer, and compared them with those collected from the ocean surface microlayer in open leads (Bigg et al., 2004). The similarity of the morphologies, chemical and physical properties of these particles strongly suggested that the airborne particles originated in the water. Many particles appeared to be microcolloids and their gels (amorphous gel-like material), called exopolymer secretions (EPS) or microgels (Decho, 1990). Other particles appeared to consist of bacteria, viruses and fragments of marine microorganisms such as diatoms.

The implication of these findings for the $\mathrm{CCN}$ cloud-radiation interaction over the pack ice area is twofold: (1) fresh EPS aggregates with gel on them could act as $\mathrm{CCN}$ directly because of the gel's strong surface-active properties; (2) those that have lost their gel could still act as sites for condensation of the oxidation products of DMS advected in confined plumes (Lundén et al., 2007) over the pack ice. The detection of insoluble marine microcolloids in most (50-90\% of total number counted) of the predominantly sulphate particles (Leck and Bigg, 2005b) is evidence of this. Their acquisition of sulphuric acid provides a much more direct and faster path to $\mathrm{CCN}$ status than growth from newly nucleated particles (Leck and Bigg, 1999).

Although these previous studies suggest that biogenically derived material from the open leads is transferred to the atmosphere, many aspects of the process remain uncertain. Bubble bursting within open leads is the most likely transfer mechanism. In the open ocean the dominant source of bubbles is the breaking of wind-generated waves (Kolovayev, 1976). Within the central Arctic, however, wind speeds are typically low, and the extent of open water within leads in the pack ice is usually modest (10-30\%) so that fetches are short and the generation of waves is limited. Leck et al. (2002) measured aerosol size spectra for cases both with and without breaking waves within open leads and concluded that film drop (centred on $100 \mathrm{~nm}$ diameter) generation depended less, and jet drop (centred on $1 \mu \mathrm{m}$ diameter) production more on wind speed than over the open ocean. The enhanced presence of film drop particles at winds speeds $<5 \mathrm{~m} \mathrm{~s}^{-1}$ suggested a source of bubbles other than from wind generated waves. Non-wave related sources of bubbles include the release of bubbles trapped in melting sea ice, expelled by freezing wa- ter (Wettlaufer, 1998), produced by the respiration of phytoplankton (Medwin, 1970; Johnson and Wangersky, 1987), or released from the sea bed (e.g. Leighton and Robb, 2008).

We present the first direct measurements of bubbles within open leads in sea ice in the central Arctic Ocean: including details of the typical size spectra, the observed variability in bubble concentrations, and to some extent their dependence on environmental conditions. Our purpose here is to evaluate the bubble measurements only; we do not attempt to assess any of the - very extensive - aerosol measurements made during the field campaign. Detailed studies of the physical and chemical properties of particles sampled from the air (below, within, and above cloud), the ocean surface microlayer, and from collected fog/cloud droplets are underway and will be presented in future papers.

\section{Measurements}

\subsection{The field campaign}

The measurements presented here were made as part of The Arctic Summer Cloud-Ocean Study (ASCOS, www.ascos. se) field campaign in the central Arctic Ocean. Based on the icebreaker Oden between 1 August and 8 September 2008, ASCOS was designed to be a highly interdisciplinary study of Arctic summer stratus and the many processes that control its properties and couple it to the surface, including: synoptic meteorology, boundary layer mean and turbulent structure, cloud macro- and microphysical properties, marine biochemistry, aerosol physical and chemical properties, and gasphase chemistry.

During the main observation period of 13 August1 September the Oden was moored to an ice floe, and drifted with it within the region $87.0-87.6^{\circ} \mathrm{N}, 1-11^{\circ} \mathrm{W}$ (Fig. 1). The ice-drift spanned the end of the summer melt season and the onset of the autumn freeze-up. The ice floe was approximately $6 \mathrm{~km}$ by $3 \mathrm{~km}$ - one of the largest in a region of closely packed ice floes of widely varying sizes (Fig. 2a).

\subsection{Bubble measurements}

The bubble measurements were made at a field site established at the edge of an open lead (Fig. 2) approximately $3 \mathrm{~km}$ from the Oden - chosen so as to avoid contamination of marine bio-chemistry samples by the ship. The width of the open lead varied from day to day with the movement of the ice from approximately $20 \mathrm{~m}$ to $100 \mathrm{~m}$. Bubble size spectra were measured with a video-based bubble imaging system with a measurement range of $27-1239 \mu \mathrm{m}$ (diameter). The sample volume $\left(20 \times 2.9 \times 1.9 \mathrm{~mm}^{3}\right)$ is imaged by a video camera, and illuminated on-axis from directly opposite the camera. Bubbles appear as a dark ring with a brighter surrounding ring and central bright spot. An automated algorithm identifies candidate bubbles, while rejecting other objects such as algae. Some images showing both bubbles and 


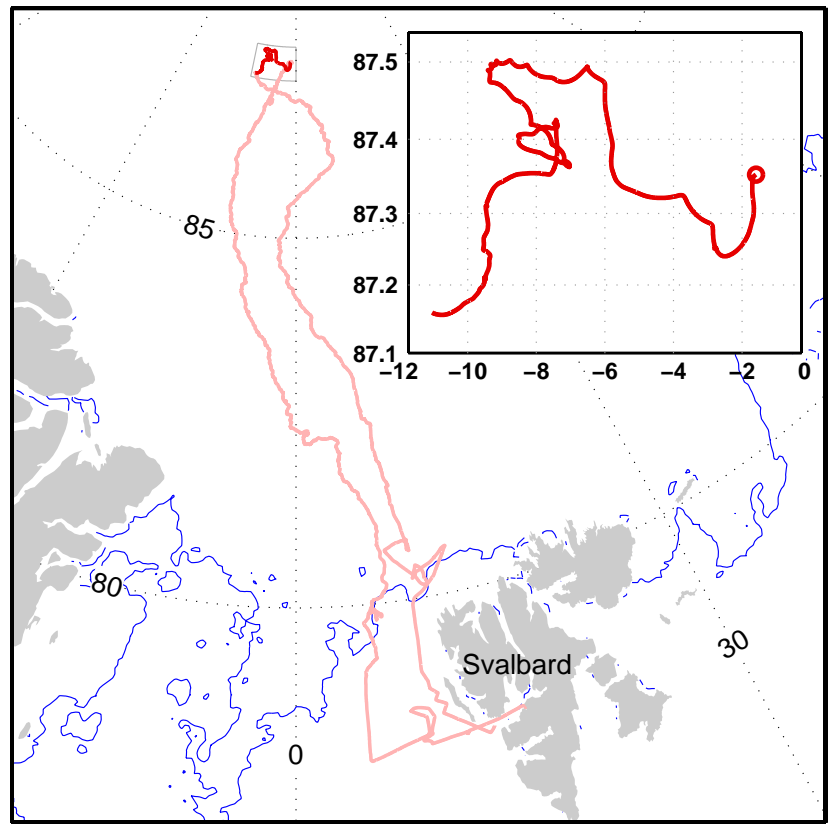

Fig. 1. Map of the ASCOS cruise track (pink) with ice-drift period highlighted (red, and inset area indicated) and (inset) shown in detail with the start of the drift marked by the circle. The ice edge (blue line) is shown for the start of the drift period on $12 \mathrm{Au}-$ gust 2008.

a variety of marine biota are shown in Fig. 3. Full technical details of the system and its image processing and bubble discrimination algorithms are given by Leifer et al. (2003). This system has previously been used to determine bubble size spectra both in the open ocean (de Leeuw and Cohen, 2001; de Leeuw et al., 2003; Brooks et al., 2009) and in the laboratory (Mårtensson et al., 2003; Sellegri et al., 2006, Fuentes et al. 2010a, b).

The bubble camera was suspended from a buoy positioned approximately $2 \mathrm{~m}$ from the ice edge, with its field of view located approximately $0.7 \mathrm{~m}$ below the surface (Fig. 4). Images were obtained in bursts of 100 frames sampled at $20 \mathrm{~Hz}$; image acquisition pauses briefly while these are written to disk and is then resumed. Data collection continued in this manner over two-minute periods at $15 \mathrm{~min}$ intervals throughout the days on which the remote field site was manned. 126 two-minute samples were obtained over a total of $32 \mathrm{~h}$ during 10 days between 17 August and 1 September; a total of approximately 194000 images. The individual bubbles identified by the image processing algorithm are sized and aggregated to produce spectra over each two-minute sampling period.

The water within the Arctic leads had much lower levels of turbulence than in the open ocean or laboratory flows in which the system has previously been used. This occasionally resulted in single bubbles becoming stuck to one of the windows through which they are illuminated and imaged,
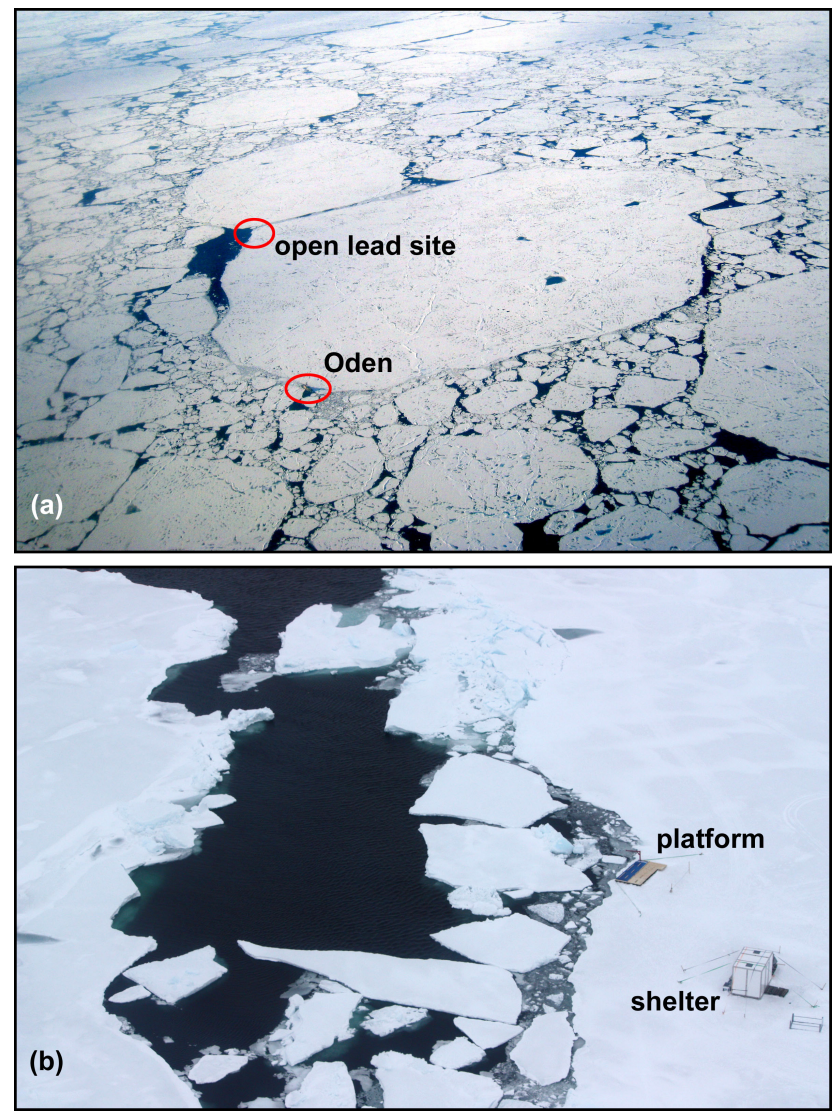

Fig. 2. (a) The ice floe on which the ASCOS measurements took place with the Oden and open lead sampling site ringed. (b) The open lead sampling site seen from the air on 14 August 2008 during a period when the wind had narrowed the lead and driven small sections of ice against the near side. The small shelter at bottom right housed the bubble camera data acquisition system and acted as an equipment store. The platform provided a secure location to take water samples from. The bubble camera was deployed close to the near side of the platform.

resulting in one bubble being repeatedly sampled throughout a large fraction of an averaging period, biasing the sample and producing a pronounced spike in the size spectra. Where such spikes were observed, all the contributing images have been individually checked, stuck bubbles identified and sized, and the spectra corrected. Figure 5 shows an example of a contaminated spectrum before and after correction.

\subsection{Measurements of mean environmental conditions}

Supporting measurements of oceanographic and meteorological conditions were obtained at sites located within about $500 \mathrm{~m}$ of the ship. A $10 \mathrm{~m}$ wind speed was derived from a logarithmic profile fit to sonic anemometer measurements on a micrometeorological mast; the near-surface air temperature was measured by aspirated thermocouples and Rotronic 


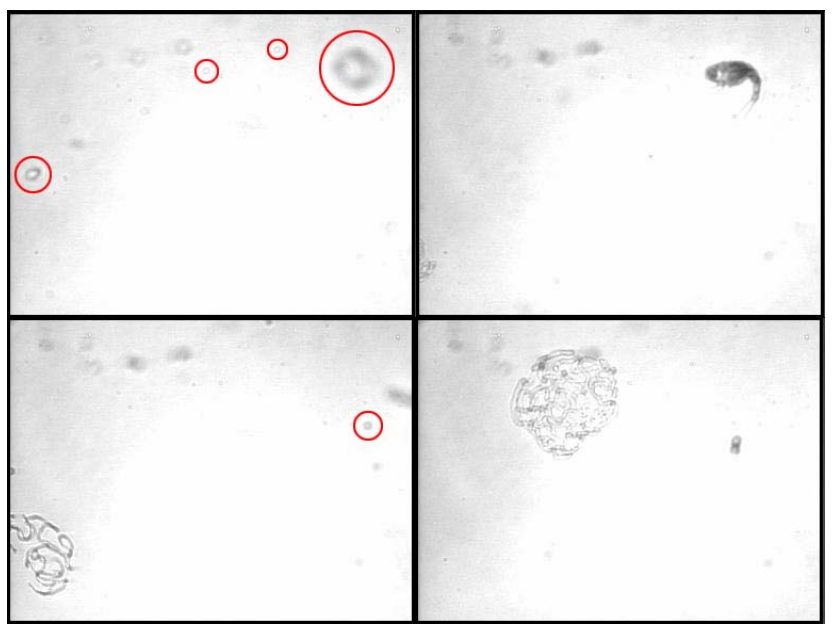

Fig. 3. Images from the bubble camera showing bubbles (circled in red), and a variety of marine biota.

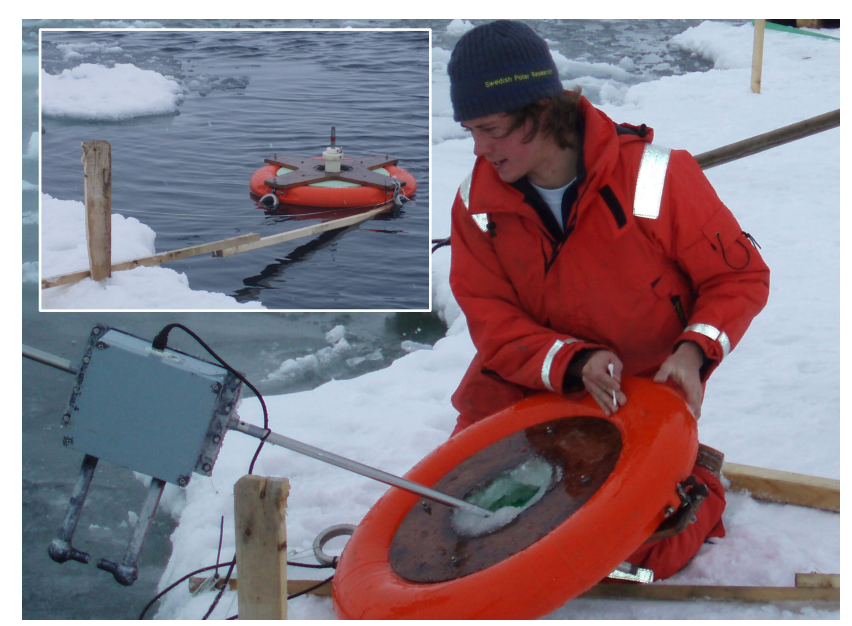

Fig. 4. The bubble camera being readied for deployment, and (inset) in position off the side of the ice floe.

hygrometer/temperature sensors on the mast; a value at $3.2 \mathrm{~m}$ is used here. Bubble measurements on 1 September were obtained while the mast was being dismantled so meteorological parameters were estimated from the ship-board weather station. Ocean current velocity relative to the ice and the turbulent fluxes were measured by a Sontek/YSI Acoustic Doppler Velocimeter mounted on a sub-surface mast located in a bore hole through the ice. Water temperature was measured by a Seabird Electronics SBE-3 sensor. While three levels of turbulence instruments were installed, only the set at a depth of $2 \mathrm{~m}$ below the underside of the ice; approximately $3.8 \mathrm{~m}$ below the ocean surface, is used here. The ice drift velocity and floe orientation are derived from continuous measurements of GPS position at the oceanography and meteorological tower sites.

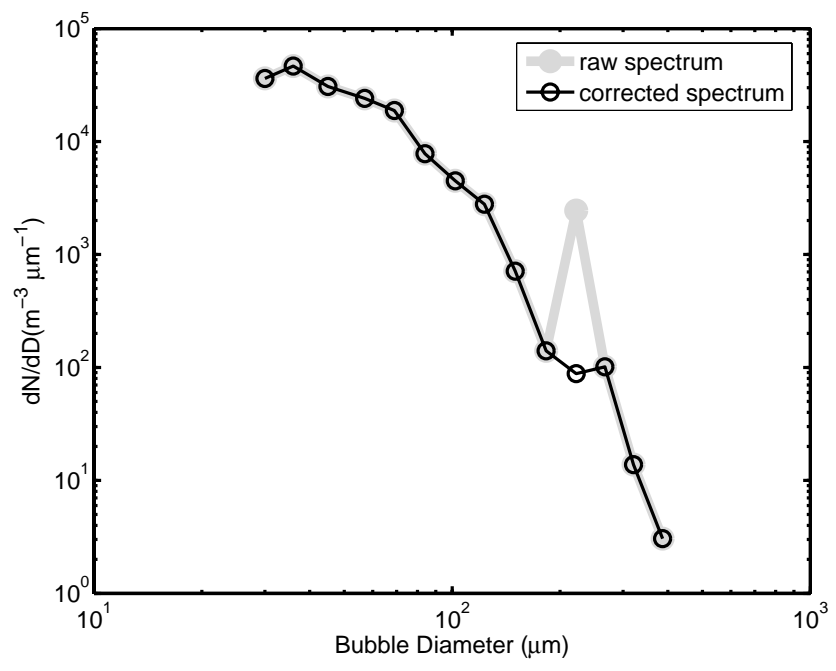

Fig. 5. An individual two-minute estimate of a bubble spectrum showing a pronounced spike resulting from multiple counting of a bubble stuck on the camera window (grey), and the corrected spectrum (black).

\section{Results}

\subsection{Bubble size spectra}

Figure 6 shows time series of mean conditions during the ice drift with the periods during which bubble measurements were obtained highlighted. During the first 4 days of bubble measurements (17-20 August) the lead was completely ice free; following a sharp drop in temperature on the $21 \mathrm{st}$ - primarily the result of cold air advected into the region the surface of the lead started to freeze and by the 22nd was covered with a layer of frazil ice about $5 \mathrm{~cm}$ deep. On the 27 th the surface of the lead opened up exposing open water again; it remained largely ice free for the remainder of the campaign although fragments of ice collected along the lead edge and around the buoy.

The maximum wind speed during the bubble measurements was $6 \mathrm{~m} \mathrm{~s}^{-1}$. The water temperature spanned a very narrow range from -1.66 to $-1.72^{\circ} \mathrm{C}$, with an average of $-1.7^{\circ} \mathrm{C}$, while the air temperature varied between 0 and $-6^{\circ} \mathrm{C}$ during the majority of the ice drift, falling to $-12^{\circ} \mathrm{C}$ early on 1 September, and rising again to $-7.5^{\circ} \mathrm{C}$ during the last period of bubble measurements. The salinity of the ocean mixed layer was approximately 32.3 psu, varying very little during the campaign. The velocity of subsurface water relative to the ice floe $\left(V_{\text {rel }}\right)$, and the drift speed of the ice $\left(V_{\mathrm{d}}\right)$ vary between 0 and $0.1 \mathrm{~m} \mathrm{~s}^{-1}$ during the measurement period and are weakly correlated both with each other (correlation coefficient $=0.46$ ) and the local wind speed (correlation coefficients $=0.5,0.36$ respectively). The drift velocity also displays a distinct semi-diurnal periodicity associated with both tidal motions and inertial currents. 


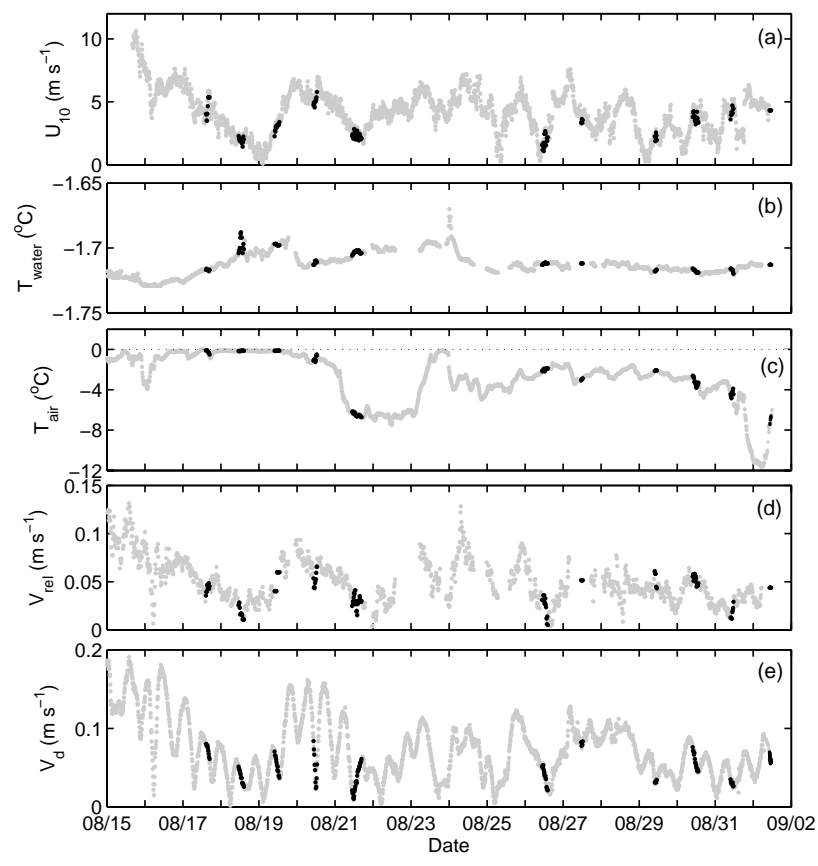

Fig. 6. Time series of mean conditions during ASCOS: (a) wind speed (U10), (b) water temperature $\left(T_{\text {water }}\right),($ c) air temperature $\left(T_{\text {air }}\right)$, (d) current speed relative to ice at $2 \mathrm{~m}$ below underside of ice (e) the drift speed of the ice floe. The black points indicate the periods during which the bubble spectra were obtained.

The mean bubble spectra for each day are shown in Fig. 7 along with a number of open ocean and surf zone spectra for comparison (The individual bubble spectra are available as a supplementary data file). The concentrations of bubbles with diameters less than $100 \mu \mathrm{m}$ are comparable to those reported in the open ocean under moderate wind speeds, of order $10 \mathrm{~m} \mathrm{~s}^{-1}$. For bubbles larger than $100 \mu \mathrm{m}$ the Arctic number concentrations decrease more rapidly with size than for the open ocean cases; the mean logarithmic gradient of $d N / d D$ with $D$ for the Arctic spectra $(D>100 \mu \mathrm{m})$ is $-5.1 \pm 0.35$, about double the mean gradient of $-2.6 \pm 0.46$ for the open ocean spectra. For mean diameters of $200-560 \mu \mathrm{m}$ the number concentrations are roughly comparable with open ocean measurements under winds of about $5 \mathrm{~ms}^{-1}$, which is approximately the minimum wind speed for which whitecapping occurs. The maximum size of bubbles observed varied from day to day between approximately 200 and $560 \mu \mathrm{m}$, very few samples contained bubbles larger than about $270 \mu \mathrm{m}$ and no bubbles were observed larger than $560 \mu \mathrm{m}$. Note that this is well below the instrument's upper detection limit of $1239 \mu \mathrm{m}$. The typical variability between the individual twominute estimates of the spectra is illustrated in Fig. 8, where the individual estimates and mean spectra are shown for 17 August and 31 August - the cases with lowest and highest mean concentrations respectively. Figure 9 shows all the individual two-minute estimates of total number concentration

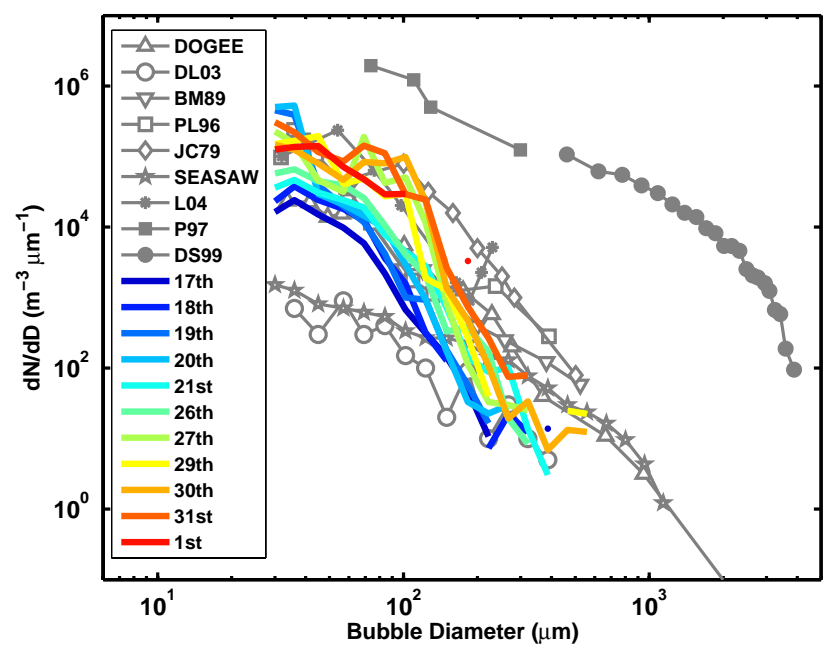

Fig. 7. Mean bubble spectra for each day (in colour). A number of open ocean (grey open symbols) and surf zone spectra (grey filled symbols) are shown for comparison. The SEASAW $\left(U=8 \mathrm{~m} \mathrm{~s}^{-1}\right)$, de Leeuw et al. (2003) (DL03, $U=5 \mathrm{~m} \mathrm{~s}^{-1}$ ), and the ASCOS data were all measured at a depth of approximately $0.4 \mathrm{~m}$ using the same optical instrument. Acoustic measurement systems were utilized in the open ocean by DOGEE (averaged over a depth of 0-3 m, $U=13 \mathrm{~m} \mathrm{~s}^{-1}$ ), Breitz and Medwin (1989) (BM89, depth $0.25 \mathrm{~m}, U=12-15 \mathrm{~m} \mathrm{~s}^{-1}$ ), Phelps and Leighton (1998) (PL98, depth $0.5 \mathrm{~m}, U=12-14 \mathrm{~m} \mathrm{~s}^{-1}$ ) and Johnson and Cooke (1979) (JC79, depth $0.7 \mathrm{~m}, U=11-13 \mathrm{~ms}^{-1}$ ), and in the surf zone by Leighton et al. (2004) (L04), Phelps et al. (1997) (P97), and Deane and Stokes (1999) (DS99). SEASAW and DOGEE measurements are summarized in Brooks et al. (2009).

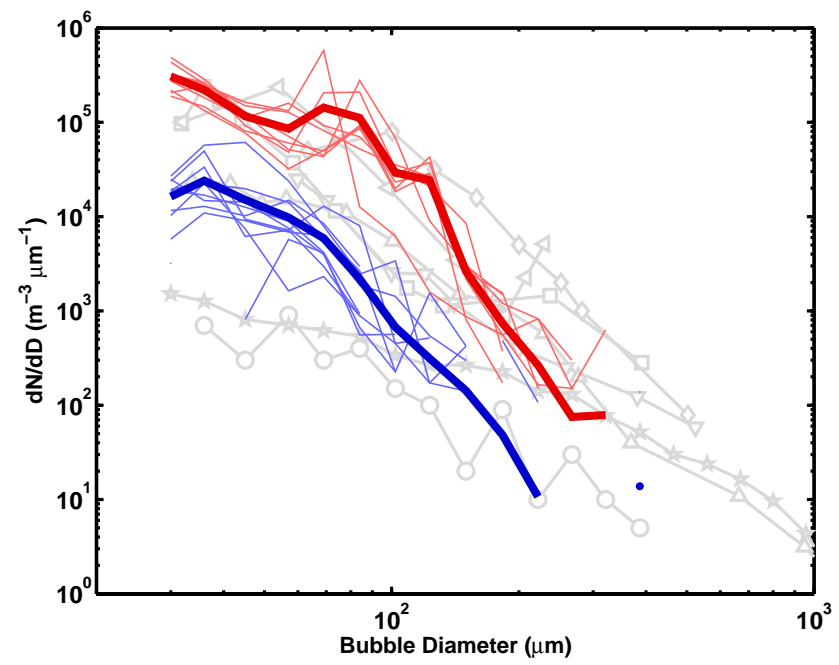

Fig. 8. The individual two-minute estimates of bubble size spectra (thin lines) for 17 August (blue) and 31 August (red) along with their means (thick lines). Open ocean spectra in grey are as Fig. 7. 


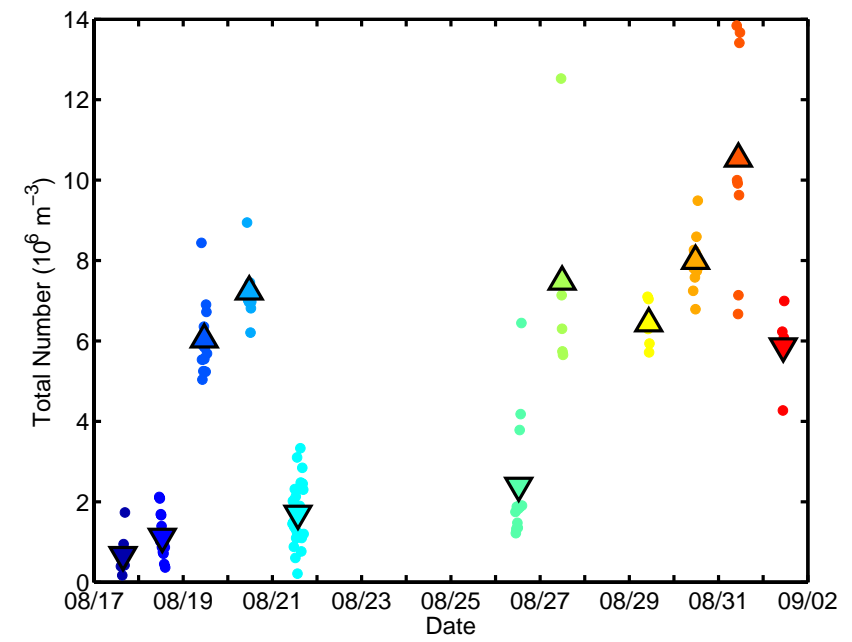

Fig. 9. Time series of individual two-minute estimates of total bubble concentrations (small dots) and their daily means (large triangles), coloured by date. Downward pointing triangles indicate that the flow was from below an ice covered surface upward pointing triangles indicate flow was from open water.

along with their daily means. The mean values span about one order of magnitude and are roughly clustered into low concentrations $\left(<2.4 \mathrm{~cm}^{-3}\right.$; on $17,18,21$ and 26 August $)$ and higher concentrations $\left(>5.8 \mathrm{~cm}^{-3}\right.$; on 19, 20,27, 29, 30, 31 August, and 1 September). The lower concentration cases correspond with cases where the lead is either mostly frozen over (21, 26 August) or the flow sampled is out from under the large ice floe on which the surface measurements were based (17, 18 August). The higher concentration cases, with the exception of 1 September, all have a local current from the lead towards the ice edge and a substantial area of open water within the lead. On 30 August the lead began to freeze over as the temperature dropped rapidly and by 1 September was completely frozen over.

Figure 10 shows the individual time series of bubble concentrations for each day. With the exception of 17 and $21 \mathrm{Au}-$ gust, all the data were collected between 09:30 to 14:00. This narrow time range precludes making any assessment of diurnal variability; however, the small diurnal variability in meteorological conditions at this high latitude means we would not expect a large diurnal signal. In general the variability between individual concentration estimates is greater than any trends over time.

\subsection{Variability with environmental conditions}

An examination of the bubble number concentration as a function of the mean atmospheric and oceanic conditions reveals little in the way of convincing relationships, with the exception of the air temperature or air-sea temperature difference. The air temperature decreases systematically over the course of the field campaign, with the exception of a cold
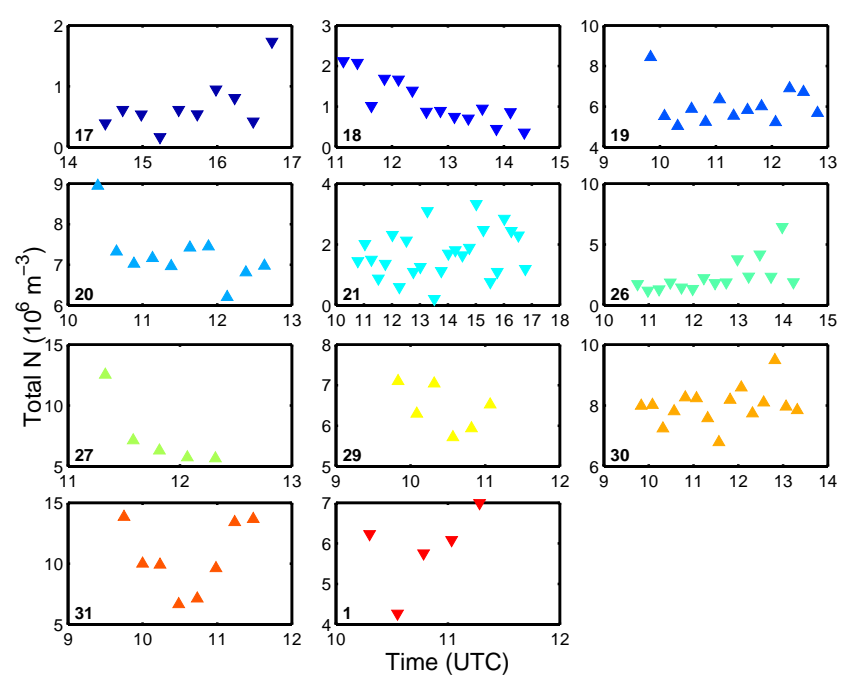

Fig. 10. Time series of total bubble number concentrations for each day. The day of the month is indicated at bottom left of each panel and also by colours matching those in Fig. 9; upward pointing triangles indicate flow from an open water surface, downward pointing triangles indicate flow from below an ice-covered surface.

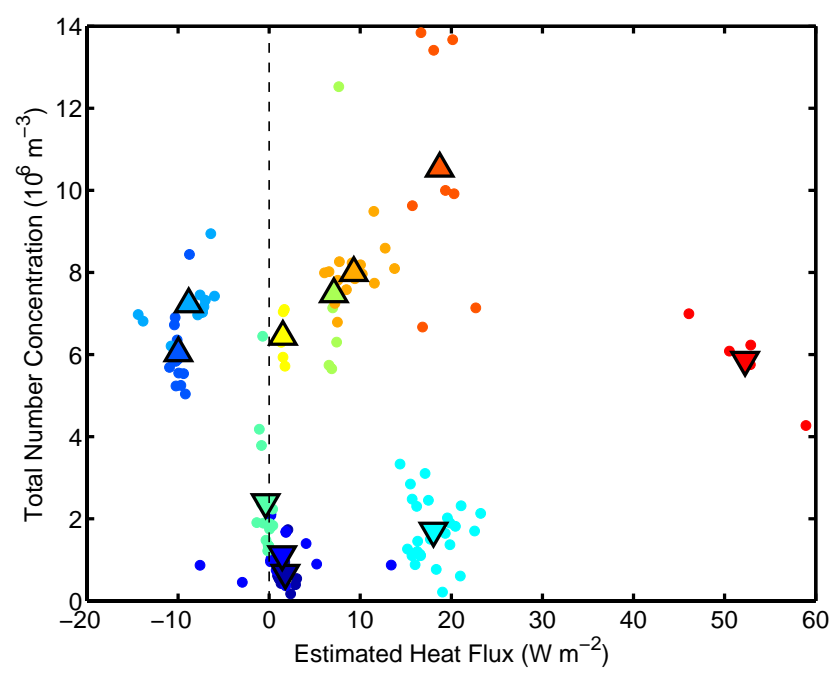

Fig. 11. Individual two-minute estimates of total bubble concentrations and daily means plotted against the heat flux at the sea-air or sea-ice interface; symbols and colours are as in Fig. 9.

period between 21 and 23 August resulting from cold air advection (Fig. 6c). The water temperature, in contrast, varies by only about $0.05^{\circ} \mathrm{C}$ over the campaign and just $0.03{ }^{\circ} \mathrm{C}$ during bubble measurement periods. Variability in air-water temperature difference is thus almost entirely determined by changes in air temperature. The primary physical link between air temperature and the ocean is provided by the surface heat flux. This is controlled by the air-sea temperature difference and the wind speed. Figure 11 shows the total bubble number concentrations plotted against the surface heat 
flux over the lead estimated from the SHEBA bulk flux algorithm (Andreas et al., 2010a, b). For cases when the lead is open a water surface is specified for the bulk algorithm and the surface temperature set to the measured water temperature; when the lead is frozen an ice surface is specified and the surface temperature set to the ice-surface temperature measured at the main meteorological mast. In practice the specification of surface type and water or ice temperature makes little difference to the estimated fluxes. On the two days when the current was from below the main ice floe (17 and 18 August) the lead surface heat flux is not representative of that experienced by water at the underside of the ice floe, which averaged $+1.2 \mathrm{~W} \mathrm{~m}^{-2}$ (upwards, from ocean to ice), and varied from 0 to $+5 \mathrm{~W} \mathrm{~m}^{-2}$. For these days the seaice heat fluxes measured at the oceanography site have been substituted for the lead surface heat fluxes. It should be noted that owing to the short fetch across the lead near-surface turbulence is unlikely to have reached a state of equilibrium and the flux can be considered an approximation only. Although direct flux measurements were made at the open lead site we use a bulk flux estimate because the flux system at the ice edge was either not operating, or the data failed quality control tests, for most of the periods during which bubble measurements were made. Where good quality flux measurements were available, the SHEBA bulk algorithm is in good qualitative agreement, but tended to overestimate the magnitude of the sensible heat flux by approximately $30 \%$; this is similar to the bias observed at the "Baltimore" site in the SHEBA flux data set (Fig. 8 of Andreas et al., 2010a). Here we are concerned primarily with relative changes in the surface flux and the bias in absolute magnitude does not affect our conclusions.

On the days on which the lead is largely ice-free, there is a distinct trend of increasing bubble concentrations with increasing positive heat fluxes (heat transfer from the surface to the atmosphere). The range of negative heat fluxes is too narrow to reveal any systematic behaviour, but on these two days (19, 20 August) the total number concentration differs little from that for the cases with positive fluxes less than $10 \mathrm{~W} \mathrm{~m}^{-2}$. Where the lead is frozen or the flow is from under the large ice floe, the bubble concentrations are much lower and show little variability and no systematic dependence on the heat flux. 1 September is an isolated case - the lead is frozen but the bubble concentration remains relatively high; this is discussed further in Sect. 4.2.

\section{Discussion}

\subsection{Implications for aerosol production}

The presence of significant numbers of bubbles within the near-surface waters of leads in Arctic sea ice provides support for a bubble-mediated mechanism for transporting highly surface-active gels with embedded aggregated mi- crocolloids into the atmosphere as suggested by Leck and Bigg (1999, 2005a) and Bigg and Leck (2008). Such materials are scavenged from the bulk water by the rising bubble and further enriched with respect to bulk sea water composition as the bubble protrudes the surface microlayer; this material is ejected into the atmosphere as film droplets and jet droplets; the composition of latter likely has a greater seawater content.

The bubbles observed here were all smaller than $560 \mu \mathrm{m}$ mean diameter and the majority (by approximately 2 orders of magnitude) were smaller than $100 \mu \mathrm{m}$. The size and number of droplets produced by a single bubble depends on the bubble size (Blanchard, 1983; Bird et al., 2010). The smallest bubbles produce only jet droplets, the largest only film droplets; the limits are not well defined, however, and depend on the properties of both water and surface microlayer. Day (1964) found a bubble diameter of $\sim 100 \mu \mathrm{m}$ to be the minimum size producing film droplets while Spiel (1998) found the limit to be $2.4 \mathrm{~mm}$; and the upper limit for the production of jet droplets to be about $3.4 \mathrm{~mm}$ (Spiel, 1997). During high wind episodes (>12 $\mathrm{m} \mathrm{s}^{-1}$ ) Leck et al. (2002) found both the film and jet drops to have a strong exponential wind-speed dependence. For low winds (around $5 \mathrm{~m} \mathrm{~s}^{-1}$ or lower) similar to this study, however, Leck et al. (2002) observed an enhanced presence of film drops. Given the bubble sizes observed here, this implies that the bubble size limits for production of jet and film droplets might differ substantially from those found in the laboratory studies cited above.

The extent to which aerosol generated from bubble bursting within the leads contributes to the overall aerosol load within the boundary layer relative to nucleation of new aerosol particles or entrainment of aerosol from above the boundary layer remains an open question. We have estimated the flux of bubbles to the surface assuming that they rise at their terminal velocity due to buoyancy. The rise velocity is estimated from a parameterization in terms of bubble size and the kinematic viscosity of water (Eq. 9 of Leifer et al., 2000). The kinematic viscosity (approximately $1.96 \times 10^{-6} \mathrm{~m} \mathrm{~s}^{-1}$ ) was estimated from the functions for seawater density and dynamic viscosity given by Sharqawy et al. (2010) and the measured temperature and salinity. Rise velocity increased from approximately $3.7 \times 10^{-4} \mathrm{~m} \mathrm{~s}^{-1}$ to $0.042 \mathrm{~m} \mathrm{~s}^{-1}$ between the smallest and largest bubbles measured. Figure 12 shows the total number flux for each individual record and the daily means. Figure 13 shows the size resolved mean flux for each day. The mean total number fluxes vary from approximately $0.1 \times 10^{4}$ to $2 \times 10^{4} \mathrm{~m}^{-2} \mathrm{~s}^{-1}$. These are of the same order as eddy covariance measurements of the total aerosol number flux made at the lead (Held et al., 2010) suggesting that bursting of bubbles at the surface might account for the observed aerosol flux.

Some caveats associated with these flux estimates are that the seawater density and viscosity functions are given only down to a temperature of $0^{\circ} \mathrm{C}$ and are here applied at $-1.7^{\circ} \mathrm{C}$; however, the functions are well behaved and 


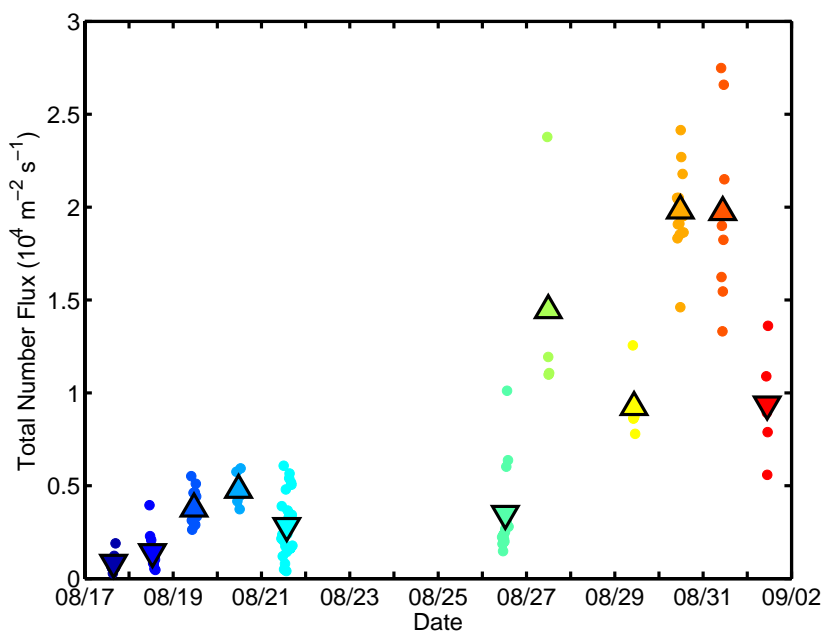

Fig. 12. The estimated total number flux of bubbles to the surface; symbols and colours are as in Fig. 9.

any resultant error is not expected to be significant. The parameterization for rise velocity is strictly valid for clean water and the presence of surfactants may significantly modify the ascent rate of bubbles. Leifer et al. (2000) note, however, that for bubbles of diameter less than about $600 \mu \mathrm{m}$ even distilled water can contain sufficient impurities to cause the bubbles to behave as "dirty" bubbles. While this implies that the estimated rise velocities should be valid for all our observed bubbles, the high concentrations of organic material in the water within the open lead means we cannot exclude the possibility of a non-negligible bias.

\subsection{Bubble production mechanism}

The measurements made during this study do not provide any information on the mechanisms by which the observed bubbles were generated, although we can be confident that they do not arise from wind generated wave breaking processes. Here we speculate briefly about a potential production mechanism. The dependence of the observed number concentration on open surface water and the surface heat flux suggests exchange processes with the atmosphere are important. A plausible mechanism is that, in the low turbulence environment of the open lead, a thin layer of surface water approaches gas saturation in equilibrium with the local atmospheric conditions. Loss of heat to the atmosphere will result in this layer of surface water being cooled below the bulk water temperature; this in turn will result in an increase in density, initiating buoyancy-driven mixing. As the surface layer sinks and mixes with warmer water below, gas solubility will decrease resulting in local supersaturation and the nucleation of bubbles. The magnitude of the surface heat flux will affect both the depression of the surface temperature below the bulk water temperature and hence the attainable supersaturation, and the strength of buoyancy driven mixing. When

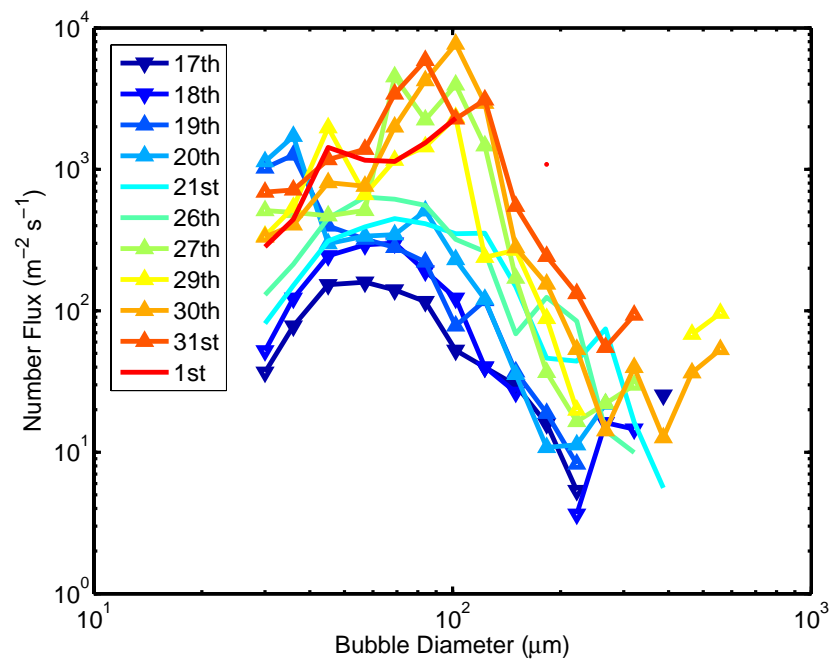

Fig. 13. The mean size resolved bubble number fluxes to the surface. Symbols and colours are as in Fig. 9, but symbols are plotted only for those days where the lead surface was not frozen over.

the lead is frozen over or the current is from below the main ice floe, gas exchange with the atmosphere is suppressed; continued heat loss through the thin surface ice may maintain convective mixing driving local fluctuations in gas saturation and continued nucleation of bubbles at a lower rate. In this case bubble production may depend on the length of time since the last contact with the open air. Active freezing at the water-ice interface will also result in degassing of the freezing water, providing a mechanism to maintain saturation in the cooled uppermost layer of water, dependent upon the rate of freezing. Such degassing may explain the relatively high bubble concentrations observed on 1 September when heat loss from the surface is high, implying that the rate of freezing and degassing is also likely to be high. This picture is consistent with the total number concentrations and their variability with the surface conditions and heat flux. Regardless of the surface conditions or whether the lead was frozen over, a minimum total number concentration of order $1 \mathrm{~cm}^{-3}$ was observed. This baseline bubble population may be maintained by one or more of a number of processes. Nucleation resulting from fluctuations in gas saturation due to mixing processes as discussed above; respiration by the substantial population of algae and phytoplankton (Medwin, 1970; Johnson and Wangersky, 1987); the release of trapped bubbles from within melting ice and the rejection of gas from freezing water (Wettlaufer, 1998). All of these are plausible mechanisms, and might all take place to varying degrees; however the limitations of the available data do not allow us to distinguish the extent to which any of them actually take place. 


\section{Conclusions}

We have presented the first measurements of bubble size spectra made within the surface waters of open leads in the pack ice of the central Arctic Ocean. Under low winds (up to $6 \mathrm{~m} \mathrm{~s}^{-1}$ ) and in the absence of breaking waves, substantial numbers of bubbles (up to $14 \mathrm{~cm}^{-3}$ ) were observed with mean diameters between $30 \mu \mathrm{m}$ (the lower detection limit of the instrument) and $560 \mu \mathrm{m}$; the shape of the spectra implies that significant numbers of bubbles smaller than $30 \mu \mathrm{m}$ are to be expected. The concentrations observed for $D<100 \mu \mathrm{m}$ are comparable with those found in the open ocean under moderate wind speeds of order $10 \mathrm{~m} \mathrm{~s}^{1}$, but at larger sizes the concentration decreases more rapidly with increasing size than do open ocean spectra; no bubbles larger than $560 \mu \mathrm{m}$ were observed. The total bubble number concentration shows two distinct dependencies on the local environmental conditions: concentrations were highest when the sampled flow has a significant fraction of surface water open to the atmosphere, and about an order of magnitude lower when the surface was completely frozen or the flow was from under the large ice floe, and thus isolated from open air for a period of order $10 \mathrm{~h}$ or more. When the surface was open to the atmosphere, the total number concentration increased with increasing heat flux from the surface to the atmosphere. This relationship supports evidence by Mårtensson et al. (2001) for the influence of environmental conditions on bubble concentrations under low to moderate wind speeds.

The presence of a significant population of bubbles provides a potential pathway for the transfer of biological material from the bulk water and surface microlayer into the atmosphere via bubble-mediated droplet production as suggested by Leck and Bigg (1999, 2005a) and Leck et al. (2002). This mechanism could provide an important but poorly understood link between cloud microphysical properties - and hence their radiative properties and the surface energy budget - and marine biochemistry in the summer central Arctic through the production of $\mathrm{CCN}$.

\section{Supplementary material related to this article is available online at: http://www.ocean-sci.net/7/ 129/2011/os-7-129-2011-supplement.zip.}

Acknowledgements. This work is part of ASCOS (the Arctic Summer Cloud-Ocean Study). ASCOS was made possible by funding from the Knut and Alice Wallenberg Foundation and the DAMOCLES European Union 6th Framework Program Integrated Research Project. The Swedish Polar Research Secretariat (SPRS) provided access to the icebreaker Oden and logistical support. We are grateful to the SPRS logistical staff and to Oden's Captain Mattias Peterson and his crew. ASCOS is an IPY project under the AICIA-IPY umbrella and an endorsed SOLAS project. The participation of SJN, IMB and CEB was funded by the UK Natural Environment Research Council (grant No. NE/E010008/1). Thanks to Andy Hind and Carlton Rauschenberg for their assistance in gathering the measurements; to R. Loughrey for checking all the raw images for stuck bubbles; to L. Cohen for advice on bubble data processing issues; and to K. Bigg and T. Leighton for valuable discussions and comments on earlier versions of the paper. Thanks for photographs are due to J. Knulst (Fig. 4, main image), S. Sjögren (Fig. 2a), and T. Strömnäs (Fig. 2b).

Edited by: W. M. Drennan

\section{References}

Andreas, M. O. and Rosenfeld, D.: Aerosol-cloud-precipitation interactions, Part 1, The nature and sources of cloud-active aerosols, Earth-Science Rev., 89, 13-41, 2008.

Andreas, E. L., Horst, T. W., Grachev, A. A., Persson, P. O. G., Fairall, C. W., Guest, P. S., and Jordan, R. E: Parametrizing turbulent exchange over summer sea ice and the marginal ice zone, Q. J. R. Meteorol. Soc., 136(B), 927-943, doi:10.1002/qj.618, 2010a.

Andreas, E. L., Persson, P. O. G., Jordan, R., Horst, T. W., Guest, P. S., Grachev, A. A., and Fairall, C. W.: Parameterizing turbulent exchange over sea ice in winter, J. Hydrometeorol. 11, 87-104, doi:10.1175/2009JHM1102.1, 2010b.

Birch, C. E., Brooks, I. M., Tjernström, M., Milton, S. F., Earnshaw, P., Söderberg, S., and Persson, P. O. G.: The performance of a global and mesoscale model over the central Arctic Ocean during late summer, J. Geophys. Res., 114, D13104, doi:10.1029/2008JD010790, 2009.

Bird, J. C., de Ruiter, R., Courbin, L., and Stone, H. A.: Daughter bubble cascades produced by folding of ruptured thin films, Nature, 465, 759-762, doi:10.1038/nature09069, 2010.

Bigg, E. K. and Leck, C.: Cloud-active particles over the central Arctic Ocean, J. Geophys. Res., 106(D23), 32155-32166, 2001.

Bigg, E. K. and Leck, C.: The composition of fragments of bubble bursting at the ocean surface, J. Geophys. Res, 113, D11209, doi:10.1029/2007JD009078, 2008.

Bigg, E. K., Leck, C., and Nilsson, E. D.: Sudden changes in arctic atmospheric aerosol concentrations during summer and autumn, Tellus, 48B, 254-271, 1996.

Bigg, E. K., Leck, C., and Tranvik, L.: Particulates of the surface microlayer of open water in the central Arctic Ocean in summer, Marine Chem., 91, 131-141, 2004.

Blanchard, D. C.: The production, distribution, and bacterial enrichment of the sea-salt aerosol, in: Air-Sea Exchange of Gases and Particles, edited by: Liss, P. S. and Slinn, W. G. N., D. Reidel, Dordrecht, 1983.

Breitz, N. and Medwin, H.: Instrumentation for in situ acoustical measurements of bubble spectra under breaking waves, J. Acoustic Soc. Amer., 86, 739-743, 1989.

Brooks, I. M., Yelland, M. J., Upstill-Goddard, R. C., Nightingale, P. D., Archer, S., d'Asaro, E., Beale, R., Beatty, C., Blomquist, B., Bloom, A. A., Brooks, B. J., Cluderay, J., Coles, D., Dacey, J., DeGrandpre, M., Dixon, J., Drennan, W. M., Gabriele, J., Goldson, L., Hardman-Mountford, N., Hill, M. K., Horn, M., Hsueh, P.-C., Huebert, B., de Leeuw, G., Leighton, T. G., Liddicoat, M., Lingard, J. J. N., McNeil, C., McQuaid, J. B., Moat, B. I., Moore, G., Neill, C., Norris, S. J., O’Doherty, S., Pas- 
cal, R. W., Prytherch, J., Rebozo, M., Sahlee, E., Salter, M., Schuster, U., Skjelvan, I., Slagter, H., Smith, M. H., Smith, P. D., Srokosz, M., Stephens, J. A., Taylor, P. K., Telszewski, M., Walsh, R., Ward, B., Woolf, D. K., Young, D., and Zemmelink, H.: Physical Exchanges at the Air-Sea Interface: Field Measurements from UK-SOLAS, Bull. Amer. Meteorol. Soc., 90, 629644, doi:10.1175/2008BAMS2578.1, 2009.

Covert, D. S., Wiedensohler, A., Aalto, P. P., Heintzenberg, J., McMurry, P. H., and Leck, C.: Aerosol number size distributions from 3 to $500 \mathrm{~nm}$ diameter in the arctic marine boundary layer during summer and autumn, Tellus, 48B, 197-212, 1996.

Curry, J. A., Hobbs, P. V., King, M. D., Randall, D. A., Minnis, P., Isaac, G. A., Pinto, J. O., Uttal, T., Bucholtz, A., Gripe, D. G., Gerber, H., Fairall, C. W., Garrett, T. J., Hudson, J., Intrieri, J. M., Jakob, C., Jensen, T., Lawson, P., Marcotte, D., Nguyen, L., Pilewskie, P., Rangno, A., Rogers, D. C., Strawbridge, K. B., Valero, F. P. J., Williams, A. G., and Wylie, D.: FIRE Arctic Clouds Experiment, Bull. Amer. Meteorol. Soc., 81, 5-29, 2000.

Day, J. A.: Production of droplets and salt nuclei by the bursting of air-bubble films, Q. J. Roy. Meteorol. Soc., 90, 72-78, 1964.

Deane, G. B. and Stokes, M. D.: Air entrainment processes and bubble size distributions in the surf zone, J. Phys. Oceanogr., 29, 1393-1403, 1999.

Decho, A. W.: Microbial exopolymer secretions in ocean environments: Their role(s) in food webs and marine processes, Oceanogr. Mar. Biol. Ann. Rev., 28, 73-153, 1990.

de Leeuw, G. and Cohen, L. H.: Bubble size distributions on the North Atlantic and North Sea, in Gas Transfer at Water Surfaces, edited by: Donelan, M. A., Drennan, W. M., Salzman, E. S., and Wanninkhof, R., AGU, Washington, DC, 271-277, 2001.

de Leeuw, G., Moerman, M., Cohen, L. H., Brooks, B. J., Smith, M. H., and Vignati, E.: Aerosol bubbles and sea spray production studies during the RED experiment, Preprints, 12th Conf. on Interactions of the Sea and Atmosphere, Long Beach, CA, Amer. Meteor. Soc., http://ams.confex.com/ams/pdfpapers/53915.pdf, 2003.

Fuentes, E., Coe, H., Green, D., de Leeuw, G., and McFiggans, G.: Laboratory-generated primary marine aerosol via bubblebursting and atomization, Atmos. Meas. Tech., 3, 141-162, doi:10.5194/amt-3-141-2010, 2010a.

Fuentes, E., Coe, H., Green, D., de Leeuw, G., and McFiggans, G.: On the impacts of phytoplankton-derived organic matter on the properties of the primary marine aerosol - Part 1: Source fluxes, Atmos. Chem. Phys., 10, 9295-9317, doi:10.5194/acp-10-92952010, 2010b.

Held, A., Brooks, I. M., Leck, C., and Tjernström, M.: On the potential contribution of open lead particle emissions to the central Arctic aerosol concentration, Atmos. Chem. Phys. Discuss., 10, 24961-24992, doi:10.5194/acpd-10-24961-2010, 2010.

Intrieri, J. M., Fairall, C. W., Shupe, M. D., Persson, P. O. G., Andreas, E. L., Guest, P. S., and Moritz, R. E.: An annual cycle of Arctic surface cloud forcing at SHEBA, J. Geophys. Res., 107(C10), 8039 pp., doi:10.1029/2000JC000439, 2002.

Johnson, B. D. and Cooke, J. C.: Bubble Populations and Spectra in Coastal Waters: A Photographic Approach, J. Geophys. Res. 84, 3761-3766, 1979.

Johnson, B. D. and Wangersky, P. J.: Microbubbles: Stabilization by monolayers of adsorbed particles, J. Geophys. Res., 92, 14641-14647, 1987.
Kolovayev, P. A.: Investigation of the concentration and statistical size distribution of wind-produced bubbles in the near-surface ocean layer, Oceanology, 15, 659-661, 1976.

Leck, C. and Bigg, E. K.: Aerosol production over remote marine areas - A new route, Geophys. Res. Lett., 26, 3577-3581, 1999.

Leck, C. and Bigg, E. K.: Evolution of the marine aerosol - A new perspective, Geophys. Res. Lett., 32, L19803, doi:10.1029/2005GL023651, 2005a.

Leck, C. and Bigg, E. K.: Biogenic particles in the surface microlayer and overlaying atmosphere in the central Arctic Ocean during summer, Tellus, 57B, 305-316, doi:10.1111/j.16000889.2005.00148.x, 2005b.

Leck, C. and Persson, C.: The central Arctic as a source of DMS: Seasonal variability in relation to biological activity, Tellus B, 48, 156-177, 1996a.

Leck, C. and Persson, C.: Seasonal and short-term variability in dimethylsulfide, sulfur dioxide and biogenic sulfur and sea salt aerosol particles in the Arctic marine boundary layer during summer and autumn, Tellus B, 48, 272-299, 1996b.

Leck, C., Bigg, E. K., Covert, D. S., Heintzenberg, J., Maenhaut, W., Nilsson, E. D., and Wiedensohler, A.: Overview of the atmospheric research program during the International Arctic Ocean Expedition 1991 (IAOE-91) and its scientific results, Tellus B, 48, 136-155, 1996.

Leck, C., Nilsson, E. D., Bigg, K., and Bäcklin, L.: The Atmospheric program on the Arctic Ocean Expedition in the summer of 1996 (AOE-96) - A Technical Overview - Outline of experimental approach, instruments, scientific objectives, J. Geophys. Res., 106, 32051-32067, 2001.

Leck, C., Norman, M., Bigg, E. K., and Hillamo, R.: Chemical composition and sources of the high Arctic aerosol relevant for fog and cloud formation, J. Geophys. Res., 107, D12, doi:10.1029/2001JD001463, 2002.

Leck, C., Tjernström, M., Matrai, P., Swietlicki, E., and Bigg, E. K.: Can Marine Micro-organisms Influence Melting of the Arctic Pack Ice?, Eos, 85, 25-36, 2004.

Leifer, I., de Leeuw, G., and Cohen, L. H.: Optical Measurement of Bubbles: System Design and Application, J. Atmos. Ocean Tech., 20, 1317-1332, 2003.

Leifer, I., Patro, R. K., and Bowyer, P.: A study on the temperature variation of rise velocity for large clean bubbles, J. Atmos. Oceanic. Tech., 17, 1392-1402, 2000.

Leighton, T. G. and Robb, G. B. N.: Preliminary mapping of void fractions and sound speeds in gassy marine sediments from subbottom profiles, J. Acoust. Soc. Am., 124, EL313-EL320, 2008.

Leighton, T. G., Meers, S. D., and White, P. R.: Propagation through nonlinear time-dependent bubble clouds and the estimation of bubble populations from measured acoustic characteristics, Proc. Roy. Soc., 460, 2521-2250, doi:10.1098/rspa.2004.1298, 2004.

Lundén, J., Svensson, G., and Leck, C.: Influence of meteorological processes on the spatial and temporal variability of atmospheric dimethyl sulfide in the high Arctic summer, J. Geophys. Res., 112, D13308, doi:10.1029/2006JD008183, 2007.

Mårtensson, M., Nilsson, E. D., de Leeuw, G., Cohen, L. H., and Hansson, H.-C.: Laboratory simulations and parameterization of the primary marine aerosol production, J. Geophys. Res., 108, 4297 pp., doi:10.1029/2002JD002263, 2003.

Medwin, H.: In situ acoustic measurements of bubble populations in coastal waters, J. Geophys. Res., 75, 599-611, 1970. 
O’Dowd, C. D., Langmann, B., Varghese, S., Scannell, C., Ceburnis, D., and Facchini, M. C.: A combined organic-inorganic sea-spray source function, Geophys. Res. Lett., 35, L01801, doi:10.1029/2007GL030331, 2008.

Phelps, A. D. and Leighton, T. G.: Oceanic bubble population measurements using a buoy-deployed combination frequency technique, IEEE J. Oceanic Eng., 23(4), 400-410, 1998.

Phelps, A. D., Ramble, D. G., and Leighton, T. G.: The use of a combination frequency technique to measure the surf zone bubble population, J. Acoust. Soc. Amer., 101, 1981-1989, 1997.

Sellegri, K., O’Dowd, C. D., Jennnings, S. G., and de Leeuw, G.: Surfactants and sub-micron sea-spray generation, J. Geophys. Res. 111, D22215, doi:10.1029/2005JD006658, 2006.

Sharqawy, M. H., Lienhard J. H., and Zubair, S. M.: Thermophysical properties of seawater: A review of existing correlations and data, Desalination and Water Treatment, 16, 354-380, 2010.

Spiel, D. E.: More on the births of jet drops from bubbles bursting on seawater surfaces, J. Geophys. Res., 102, 5815-5821, 1997.
Spiel, D. E.: On the birth of film drops from bubbles bursting on seawater surfaces, J. Geophys. Res., 103, 24907-24918, 1998.

Tang, I. N., Tridico, A. C., and Fung, K. H.: Thermodynamic and optical properties of sea salt aerosols, J. Geophys. Res., 102, 23269-23275, doi:10.1029/97JD01806, 1997.

Tjernström, M., Sedlar, J., and Shupe, M. D.: How well do regional climate models reproduce radiation and clouds in the Arctic?, J. Appl. Meteor. Climatol., 47, 2405-2422, 2008.

Tjernström M., Zagar, M., Svensson, G., Cassano, J. J., Pfeifer, S., Rinke, A., Wyser, K., Dethloff, K., Jones, C., Semmler, T., and Shaw, M.: Modelling the Arctic Boundary Layer: An Evaluation of Six ARCMIP Regional-Scale Models Using Data from the SHEBA Project, Boundary Layer Meteorol., 117, 337-381, doi:10.1007/s10546-004-7954-z, 2005.

Wettlaufer, G.: Introduction to crystallization phenomena in natural and artificial sea ice, in The Physics of ice covered seas, edited by: Lepparantä, M., Univ. of Helsinki, Helsinki, 105-195, 1998. 